Vol. VIII - REVISTA DE HISTÓRIA - Ano V

\title{
CONFERENCIA
}

\section{CAPISTRANO DE ABREU, O HISTORIADOR E O HOMEM (1).}

Aqui estamos reunidos para cultuar a memória de um homem que foi um gigante do espírito, um homem que laboriosamente logrou reunir uma cultura tão vasta, tão profunda e completa, que dêle podemos dizer, repetindo Sílvio Romero:

"... foi uma enciclopédia viva, tôda uma academia de ciências, completa sociedade de História, um curso vivo de Humanidade, um saber polimórfico, um oceano de conhecimentos".

Realmente, se aqui estamos nesta Sociedade de Estudos Históricos, para homenagear a figura de Capistrano de Abreu como historiador, não devemos nos esquecer que, além de grande historiador, Capistrano foi briihante jornalista, crítico, filólogo, etnólogo, geógrafo, sociólogo e filósofo da História. Foi um erudito em tôda a expressão da palavra. Realizou o milagre de absorver a totalidade dos conhecimentos científicos e literários de sua época. Foi um sábio consagrado nos centros mais cultos da América e da Europa.

Humberto de Campos considerou-o "a inteligência mais aguda e pronta que as letras brasileiras já tiveram a seu serviço" (2).

Para Nelson Werneck Sodré, Capistrano foi "um dos últimos exemplares humanos em que a erudição se apresentou entre nós, com tôdas as suas deficiências e tôdas as suas grandezas" (3).

\section{O HISTORIADOR}

Vamos aqui tentar a difícil tarefa de analisar uma das facetas dêsse talento multiforme - o historiador.

Capristrano é o verdadeiro criador da moderna História do Brasil. Antes dêle, os tratados de História Pátria não passavam

(1). - Conferência pronunciada no Salāo Nobre da Faculdade de Filosofia, Ciências e Letras da Universidade de São Paulo, patrocinada pela Sociedade de Estudos Históricos, no dia 24-XI-1953, em comemoração do Centenário do nascimento de Capistrano de Abreu.

(2). - Apud Rodrigo Otávio Fitho, A vida de Capistrano de Abreu, in "Jomal do Comércio" de 27 de setembro de 1953.

(3). - Nelson Werneck Sodré, Capistrano, in "Correio Paulistaco" de 4 de , outubro de 1953. 
de crônicas cansativas, incolores relatórios que produziam sonolência, memórias sensaboronas que exploravam incidentes insignificantes de nossa Cronologia. E, o que era pior! - desfiavam rosários de nomes e títulos de comandantes de esquadras, de capitães-mores, de governadores gerais, formando um todo mal concatenado, que produzia ogeriza mesmo aos que tivessem vocação para os estudos históricos.

Em Capistrano, quão longe estamos dêsse amontoado de fatos e nomes, ordenados mais ou menos cronològicamente! Em sua obra, que diferença! Na sua história vibra e palpita a alma do povo brasileiro. Nela há raciocínio e lógica. Nela há interpretação e crítica.

Desde muito jovem, sonhou Capistrano escrever uma verdadeira História do Brasil. Sonhou quebrar os quadros de ferro em que ela fôra aprisionada. Projetou escrever uma História do Brasil onde as guerras flamengas e espanholas fôssem substituídas pela epopéia do bandeirismo, pela revelação das minas de ouro, pela gigantesca obra que foi a abertura dos caminhos nos sertões inóspitos, pela criação de gado que determinou a posse da terra, fatos relegados ao esquecimento pelos historiadores que o precederam (4).

Em carta a João Lúcio de Azevedo, diria êle certa ocasião: - "Não há questão mais importante para a História do Brasil do que a ruptura da grande curva do São Francisco, a passagem dos Cariris e da Borborema, a entrada no Parnaiba, o caminho terrestre do Maranhão à Bahia"! (5) .

Com essa mentalidade nova, Capistrano remodelou a historiografia brasileira. Para êle não era a História Militar, a Política ou a Administrativa que interessavam. Seu interêsse voltava-se para setores que nunca haviam merecido a atenção de ninguém - o devassamento do território, o povoamento, a evolução econômica, a história dos caminhos, a miscigenação, a formação psicológica da nacionalidade brasileira.

Por tudo isso, foi um pioneiro. Um abridor de picada. Um cérebro criador.

Fazer História do Brasil amontoando fatos e nomes, é fácil.

Para realizar a História Pátria, como a queria Capistrano, era preciso conhecer profundamente História Universal, Geografia, Etnografia, Antropologia, Psiocologia dos Povos, Economia Política, Filologia, assim como as ciências auxiliares da História Arqueologia, Paleografia, Numismática. Era preciso conhecer Taine, Wundt, Martius, Carlyle, Schmmoller, Spencer, Ratzel, Breysing, Buckle, Pshol, Wappaeus e muitos outros autores, os quais, poliglota que era, lia nas línguas originais.

(4). - Carta de Capistrano a Rio Branco, apud José Honório Rodrigues, Como nas ceram os Capítulos de História Colonial, in "Digesto Econômico" n. 107, pág. 88 , outubro de 1953.

(5). - Carta a João Lúcio de Azevedo, apud José Honório Rodrigues, loc. cit. 
Paradoxalmente, Capistrano que é considerado o criador da moderna historiografia brasileira, não escreveu uma completa História do Brasil, como todos esperavam dêle, sendo como era o que em melhores condições estava para o fazer.

E' que, para elaborar a História do Brasil, nos moldes em que a desejava Capistrano, era mister completa revisão das fontes, era imprescinđível um trabalho preparatório de busca e agrupamento de documentos, enfim, fazia-se necessário pesquisar.

O trabalho árduo de investigar, de rebuscar arquivos, ao qual se dedicou apaixonadamente, como veremos mais tarde, rouboulhe o tempo que teria tido para escrever a História completa do Brasil.

Capistrano era como um artista que, sentindo dentro de si a fôrça criadora para realizar uma obra prima, tivesse que inicialmente fabricar êle mesmo as ferramentas, consumindo nessa ingrata tarefa, largo espaço de tempo e as melhores reservas de energia.

Por outro lado, outros ramos científicos atraíram seu espírito ávido de conhecimentos. Capistrano deixou obra criadora não só em História, como em Etnografia. Antropogeografia e em. Sociologia.

Todavia, se a obra de Capistrano, como historiador, é pouco volumosa, seu valor é incomensurável, porque lançou os fundamentos, os alicerces, a orientação da moderna historiografia brasílica.

Sua obra histórica não se resume aos volumes que deixou. Devemos vê-la também nas pesquisas que realizou pessoalmente e nas que incentivou e promoveu; na formação que deu aos seus discípulos, nos problemas que resolveu ou simplesmente agitou, nas picadas que abriu e nas veredas que simplesmente deixou entrever, para que outros, em lugar dêle, as palmilhassem.

Sua obra, é obra de Mestre! Nela encontramos a pesquisa, a análise do documento, a mais completa probidade na citação das fontes, o agrupamento filosófico dos acontecimentos, a independência no julgamento, a crítica interpretativa e, sobretudo, conclusões.

Além de modêlo no método, Capistrano foi modêlo no estilo. Em verdade, criou o estilo histórico. Fugindo ao gongorismo à Rocha Pitta, à linguagem empolada que freqüentemente encobre o vazio de idéias, Capistrano tem a frase simples, límpida, correta, própria de um cientista. Sem adjetivação e rebuscamento, rica de elegância e conteúdo!

A obra histórica de Capistrano é, acima de tudo, original. Pela orientação que imprime aos seus estudos, pelas interpretações que tira dos fatos, pelos próprios fatos que põe em relêvo (que nada têm a ver com a surrada história político-administrativa 
ou militar) apciados em sólida documentação, que sua paciência. beneditina arrancava às gavetas dos arquivos.

Sua obra principal, Capítulos da História Colonial é uma jóia primorosa de nossa historiografia. E' uma preciosa sintese, na qual sentimos que cada miruto de leitura, representa anos de trabalho de análise, de estudos, de pesquisas, de amadurecimento de idéias.

E' um trabalho que foi acolhido com louvores unânimes da. crítica e até hoje, decorrido meio século de sua aparição, é considerado modelar.

Foi escrito em apenas 10 meses, às carreiras, porque o editor dera-1he estreito limite de tempo para sua elaboração. Capistrano trabalhou como um galé, com o editor a amofiná-lo, para que. entregasse os originais (6).

Evidentemente, sendo obrigado a produzir um trabalho científico com tal premência, Capistrano não pôde dar à obra tươo. que poderia dar. E, por isso mesmo, confidenciaria a um amigo:

- "Se me perguntares se eston satisfeito com o que fiz, dir-te-ei francamente, nâo! Imaginava outra coisa e não pude realizá-la, parte por minha culpa, parte por culpa das circunstâncias. Acreditei muito na extensão da vida e na brevidade da arte, e fui punido" (7).

Sentia por sua obra ódio e nojo, ao mesmo tempo, sabia que aquêle trabalho era simplesmente o arcabouço de uma obra vigorosa que êle deveria e poderia construir (\$).

Desde o momento em que colocou o ponto final nos Capitulos já tencionava refazê-los, completá-los, corrigir-lihe as falhas, preencher-the as lacunas.

Todavia, apesar das sucessivas reedições, os Capitulos nunca foram modificados na essência, como Capistrano tencionava e desejava. A vida não lhe ceu tempo. Outras obras o absorveram.

E, aí estão os Capítulos da História Colonial que, apesar do descontentamento de Capistrano, constituem ainda hoje uma obra: prima da historiografia brasileira.

Outro importante trabalho de Capistrano, foi a tese de concurso $O$ descobrimento do Brasil, que ainda não foi superada.

O Prefácio e as Anotações à História de Frei Vicente do Salvador, demonstram eloqüentemente a erudição de nosso homenageado. Não houve detalhe que deixasse confuso, não houve minúcia que não esclarecesse. Foram tão sólidas as anotações que fêz ao texto de Frei Vicente que, anotações e texto se integraram

\footnotetext{
(6). José Honório Rodrigues, lac. cit.

(7). - Carta a Studart de 28 de novembro de 1906, apud José Honório Rodri-

(8). - Carta a Studart de 7 de jareiro de 1907 , apud José Honório Rodrigues,
loc. cit.
} 
num todo tão coeso que, no dizer de Nelson Werneck Sodré, a obra é mais de Capistrano do que de Frei Vicente (9).

Alberto Rangel, após ler os Prolegômenos capistraneanos à obra de Frei Vicente, apenas pôde balbuciar: - "Mas como êste homem sabe. Como sabe e ressabe" (10).

Idêntica obra de beneditina paciência iniciou Capistrano, anotando a História Geral de Varnhagem, tarefa difícil, se lembrarmos que Varnhagem tinha o hábito de não citar as fontes utilizadas. Coube à Capistrano a difícil missão de preencher essas lacunas, completar e alargar a obra de Varnhagem. Infelizmente, a morte interrompeu-ihe a tarefa no II volume, tendo-a prosseguido seu discípulo Rodolfo Garcia.

Afora êsses trabalhos, Capistrano publicou na imprensa e em revistas, preciosos artigos que vêm sendo reunidos em volumes pela "Sociedade Capistrano de Abreu", que já editou Caminhos antigos e Povoamento do Brasil e mais três volumes da série Ensaios e Estudos.

\section{O PESQUISADOR}

Muito mais poderia ter produzido Capistrano. Se não o fêz foi em virtude de sua arraigada honestidade científica. Ele conhecia mais do que ninguém as deficiências e as lacunas de nossa historiografia.

Sabia que pouco se poderia fazer em História do Brasil, enquanto novas fontes não fôssem dominadas e divulgadas. E' célebre sua frase:

"No Brasil, não precisamos de História, precisamos de documentos" (11).

Ele sonhava refazer a nossa História, mas refazê-la apoiađo em sólida base documental. Torturava-o a idéia de escrever uma História do Brasil, sem conhecer os tesouros em documentos brasileiros, sepultados nos arquivos portuguêses, nos de Sevilha e Simancas, nos arquivos holandeses, inglêses, franceses e italianos.

Do Rio de Janeiro, êle dirigia pesquisas na. Europa. Consultava arquivistas, principalmente portuguêses. Insistia com amigos para que procurassem esta ou aquela peça documental.

Disse, certa ocasião, em carta a Lino de Assumpção:

"A História do Brasil é um mundo e o que existe nos arquivos portuguêses, é pelo menos um continente".

Capistrano odiava os que, para escrever História apenas se limitam a dizer o que os outros já disseram, usando em lugar da pesquisa, que renova, apenas o recurso da sinonímia. Chamava

(9). - Nelson Werneck Sodré, loc. cit.

(10): - Apud Afonso Taunay, Capistrano de Abreu, in "Fôlha da Manhã" de 25 de outubro de 1953

(11). - Carta João Lúcio de Azevedo de 17 de maio de 1920, apud José Honório Rodrigues, in $A$ pesquisa histórica no Brasil, Dep. de Imprensa Nacional, Rio, 1952. 
a êsses repetidores "tiririca" invasora das nossas revistas, ocupando o lugar que deveria ser dado a trabalhos sérios.

Sua paixão pela História do Brasil fêz dêle um pesquisador apaixonado. Sua obra como pesquisador, incentivador de pesquisas e promotor da divulgação de fontes históricas, é tão relevante quanto o de historiador. Poderosa atuação teve junto aos poderes. públicos, para a efetivação da pesquisa de Manuel Cícero, da qual resultou a feitura de precioso catálogo dos documentos brasileiros existentes no Arquivo do Conselho Ultramarino, que foi útil näo só a brasileiros, como a portuguêses, como o confessou João Lúcio de Azevedo (12).

Seu cérebro esclarecido não admitia a ereção da História do Brasil, em bases defintivas, sem a prévia divulgação das fontes, dos manuscritos. Batalhador ferrenho da publicação de documentos, disse certa vez:

"O mal das revistas de nossos Institutos, é dar tão pouco abrigo aos documentos. Imprimem em seu lugat imensos discursos, logorréia que quase sempre não passa de verdadeira morifanada".

E, com amarga ironia, acrescentou:

"Ainda é bom quando nesta verborragia limitam-se os discursadores a repetir o que os velhos autores escreveram e não se metem a irvulgar e sobretudo a inventar. Ah! se os nossos Institutos a exemplo do que fêz Stưdart no do Ceará, reservassem espaço à divulgação dos documentos. Quantas milhares de páginas teríamos hoje, de páginas úteis, em vez daquilo que existe, tendo consumido tantos e tantos contos de réis, empregados na propagação de babozeiras" (13).

Chegou Capistrano a projetar uma Sociedade em que todos os membros pagassem uma modesta cota mensal, com o objetivo de se manter permanentemente um copista em Portugal, transcrevendo documentos que interessam à nossa História, existentes nos Arquivos do Tombo e Ultramarino.

Dessa sua preocupação sadía de divulgar as fontes, surgiram à luz numerosos textos que provocaram verdadeiro abalo na historiografia brasileira, como-por exemplo as obras completas de Fernão Cardim, as Informações e Fragmentos do Padre José de Anchieta, a Fistória de Frei Vicente do Salvador, os Documentos Relativos à Visitação do Santo Ofício à Bahia e Pernambuco e outros.

Não podemos deixar de notar a influência decisiva que exerceu na publicação da Coleção Eduardo Prado, realizada por Paulo Prado, seu amigo e discípulo, atendendo a seu conselho.

Tais publicações significavam a presservação de preciosas peças documentais que, não fôsse Capistrano, estariam até hoje

(12). - José Fonório Rođrigues, A pesquisa histórica no Brasil, pág. 116.

(13). - Afonso Taunay, Capistrano de Abreu, in "Fôlha da Manhä" de 25 de outubro de 1953 . 
entumuladas nas gavetas dos Arquivos, ou teriam sido devoradas pelo caruncho.

Significavam, também, pôr os instrumentos de trabalho nas mãos de todos aquêles que quisessem se dedicar à História do Brasil.

Não havia em Capistrano nem sombra da feia mácula que recai sôbre alguns de nossos historiadores, que escamoteiam a documentação para seu uso exclusivo, "esquecem" de fazer citações, como que temendo possível concorrência.

Com que grandeza de alma, com que legítimo prazer espiritual, Capistrano punha ao alcance do público os manuscritos, as obras raras que sua extraordinária intuição histórica descobria nos Arquivos!

Deve-se à extraordinária intuição de Capistrano, a solução de importantíssimos problemas de nossa historiografia.

Por exemplo, a descoberta do autor do precioso livro Cultura e Opulência do Brasil, por súas Drogas e Minas. Essa obra grandiosa, que tem a auréola do confisco e quase destruição, por parte do govêrno português, mercê dos preciosos informes que divulga no tocante à economia colonial, fôra publicada no dealbar do século XVIII (1711), sob os pseudônimos de "André João Antonil" e "Anônimo Toscano".

Descobrir a verdadeira identidade de Antonil, foi um dos problemas que mais apaironou bibliófilos lusos e brasileiros.

Capistrano, que aliava à sólida erudição, singular intuição para a História, revelou o segrêdo da criptonímia de Anônimo Toscano. Antonil, revelou Capistrano, não era outro senão o jesuíta João Antônio Andreoni, nascido na Toscana e que exєrceu no Brasil os cargos de Reitor e Provincial (14).

Outro esclarecimento que nossa bibliografia histórica deve a Capistrano, foi a revelação das obras completas do Padre Fernão Cardim. Dêle só se conhecia uma narrativa epistolar, versando sôbre a Missão jesuítica que esteve no Brasil, entre 1583 e 1590 .

A paciência beneditina de Capistrano permitiu que se conhecessem dois outros tratados de Fernão Cardim: Do Clima e terra do Brasil e Do princípio e origem dos indios do Brasil. Tais trabalhos haviam sido publicados em inglês, na obra de Purchas, Pilgrimages, em 1625, sob o título $A$ treatise of Brazil written by a Portugal (sic) wich had long lived there.

Capistrano, após estafantes pesquisas, apurou que eram de Fernão Cardim êsses dois trabalhos, sendo que os originais haviam sido roubados ao dono, num ataque do corsário Francis Cook, que sofrera o navio em que o clérigo viajava, nas proximidades de Portugal, no ano de 1601.

(14). - Afonso Taunay, prefácio à Obra de Antoni1, Cultura e Opulência do Brasil por suas drogas e minas, Edição Melhoramentos, São Paulo, 1921. 
Levados os originais para a Inglaterra, reapareceram impressos na coleção Purchas, e aí ficaram anônimamente, até Capistrano revelar o mistério de sua autoria (15).

Assim, mais uma dívida contraímos com Capistrano, graças a quem, dois trabalhos escritos em fins do século XVI, tiveram sua autoria comprovada e tôda a obra de Cardim pôde ser reunida num único volume, intitulado Tratado da Terra e da Gente do Brasil.

Outro apaixonante problema que Capistrano desvendou, com a cooperação de Rodolfo Garcia, foi o da autoria dos Diálogos das grandezas do Brasil.

Estudando a tão discutida autoria, disse êle que havia duas pistas para se chegar a estabelecer o autor dos Diálogos. Louvando-se no que dissera Brandonius (um dos personagens dos Diálogos) o autor da obra tinha a seu cargo, em 1583, o recebimento dos dízimos do açúcar na Capitania de Pernambuco e era novo na terra.

Percorrendo documentos existentes na Biblioteca do Instituto Histórico, averiguou Capistrano que o arrematador dos dízimos do açúcar, naquela data, era Bento Dias Santiago, mas êste não era novo na terra, pois que outros documentos o revelavam morador em Pernambuco desde 1565.

Não sendo êle novo na terra, devia-se procurar a autoria dos Diálogos, raciocinou Capistrano, em seus prepostos ou feitores, encarregados por Santiago de receber os dízimos.

A outra pista que ofereceu Capistrano era a seguinte: o autor dos Diáloğos, seguramente, deveria se chamar Brandão, tendo alatinado seu nóme para "Brandônio".

Estudando todos os possíveis Brandões que viveram naquela época, Capistrano chegou à conclusão de que o único que tinha probabilidades de ser o autor dos Diálogos era Ambrósio Fernandes Brandão.

Veja-se os têrmos de Capistrano: "o único que tinha probabilidades". Ele não poderia afirmar "é êste!", por não ter documentos em que se apoiar. Mas sua intuição the dizia: "é o único que tem probabilidades de ser o autor".

Capistrano estabeleceu duas premissas: de um lado, o autor dos Diálogos só poderia ser recebedor dos dízimos. Por outro lado, só poderia se chamar Brandão. Faltava um elo que ligasse as duas pistas.

O elo foi encontrado por seu discípulo Rodolfo Garcia que, dentre a documentação referente à Visitação do Santo Ofício ao Brasil, encontrou provas de que Ambrósio Fernandes Brandão foi um dos feitores ou escrivães de Bento Dias Santiago. Provou mais - provou que Ambrósio Fernandes Brandão, o "Brandônio" dos

(15). - Jaão Capistrano de Abreu, Ensaios e Estudos, 2a, série, pág. 325 e segs. 
Diálogos, tinha um amigo intimo, seu companheiro de trabalho e de tôdas as horas, chamado Nuno Álvares.

Eram amigos, companheiros e exerciam cargos idênticos. Esse Nuno Alvares é, certamente o interlocutor de Brandônio, aparł-cenco seu nome português Álvares, alatinado para Alviano, nos Diálogos (16).

Assim, caiu por terra a hipótese errôneamente aventada e que infelizmente se propagara amplamente, de que a autoria dos Diálogos era de Bento Teixeira Pinto.

\section{O PROFESSOR}

Capistrano tem ainda a exaltar sua poderosa personalidade, a auréola de Professor.

Tendo vagado a Cadeira de Corografia e História do Brasil do Colégio Pedro II, concorreu a ela com a tese: Descobrimento do Brasil e seu desenvolvimento no século $X V I$, hoje obra clássica, naquela época, revolucionária.

Ao lado da exposição elegante, encontrava-se em sua tese erudição, pesquisa, espírito de síntese, interpretação e conclusões.

Com êsse vigoroso trabalho, aos 27 anos, venceu o difícil concurso, tendo derrotado figuras de grande destaque intelectual, inclusive a pessoa que já vinha interinamente exercendo o cargo.

Ser professor do Colégio Pedro II, naquela época, era uma das mais destacadas posições intelectuais que se poderia atingir. Verdadeiras sumidades faziam parte do corpo docente do estabelecimento criado por Pedro II, e que era, realmente, a menina dos olhos do Monarca. O Imperador, pessoalmente, fiscalizava os concursos para as cátedras, exigindo o mais absoluto rigor na seleção do professorado.

Capistrano não dispunha de dotes de oratória. Apesar de em suas aulas não haver a atração da palavra sonora, foi um Mestre na mais alta acepção do vocábulo. Tornou-se um centro de irradiação cultural, um Chefe de Escola, renovando não só o ensino da História, como o da Geografia.

A forma clássica de ensinar essas duas disciplinas, era pôr à prova a memória dos estudantes, com a decoração de datas, nomes, acidentes geográficos e outras coisas inexpressivas. Capistrano faz apoiar as duas disciplinas no raciocínio, dando-lhes caráter de ciência. Sua preocupação, como professor, não era narrar, mas fazer compreender, interpretar, criticar.

E' relevante lembrar que, na época em que Capistrano tornou-se professor, a História do Brasil tinha se tornado tão tediosa que causava horror a estudantes e a adutlos. Podia-se encontrar

(16). - Almir de Andrade, Os primeiros estudos sociais no Brasil, pág. 143, nota 255. Edição José Olimpio. Rio, 1941. 
nos meios cultos das capitais brasileiras, alguns apaixonados cultores da heróica história helênica ou da vigorosa história romana. Muitos intelectuais se interessavam pela história da França e da Inglaterra. A História do Brasil, porém, era tão desprezada que, como o disse Veríssimo, com exceção de Varnhagem, era com estrangeiros, como Southey, Armitage, que se ia aprender a História de nosso país (17).

Em tal descaso recairam os estudos das coisas brasileiras, que houve uma reforma de ensino pela qual a Cadeira de Corografia e História do Brasil foi abolida, subordinando-se êsses estudos à História Geral.

Nesse momento, Capistrano que era acima de tudo um homem honesto, pediu para ser posto em disponibilidade, pois que, em sua modestia, "julgava-se apenas especialista em História e Geografia Pátrias".

Esse homem, cuja erudição até hoje causa assombro, julgouse incompetente para um cargo, que sabe Deus, quantos ilustres desconhecidos correram a disputar.

Aftastado do Colégio Pedro Il, sua ação como professor e renovador dos estudos históricos e geográficos continuou, através de intensa correspondência mantida com antigos discípulos e amigos, que dêle recebiam conselhos, esclarecimentos, incentivo para trabalhar no desvendamento das coisas de nosso passado.

Essa correspondência, que breve será publicada, revelará Capistrano, como um gigante de nossa historiografia (18).

Prosseguiu também pela imprensa, através de copiosa colaboração, sua corajosa luta para colocar o estudo da História do Brasil, no plano científico em que deveria estar.

Sua grandeza como Mestre, pode ser medida pela altura intelectual de seus principais discípulos, dentre os quais podemos destacar Taunay e Rodolfo Garcia.

\section{O HOMEM}

Esse gigante do espírito era de uma simplicidade e modéstia extraordinárias. Nem sequer compreendia como aquilo que fazia, por simples amor ao estudo, pudesse suscitar a admiração do país inteiro.

Não dava apreço à sua obra. Não ligava. importância aos seus escritos. Não os guardava. Muitos publicava sem assinatura, - que dificulta muito a organização de sua bibliografia.

A Biblioteca Nacional guarda alguns de seus estudos, rascunhos que o IMestre esquecia no Salão de Leitura, após longas horas de exaustivas pesquisas.

(17). - José Veríssimo, A Edurcação Nacional, 2a. Edição, págs. 126-127. Rio, 1906.

(18). - A correspondência de Capistrano está sendo ordenada para breve publicação, por José Honório Rođrigues. 


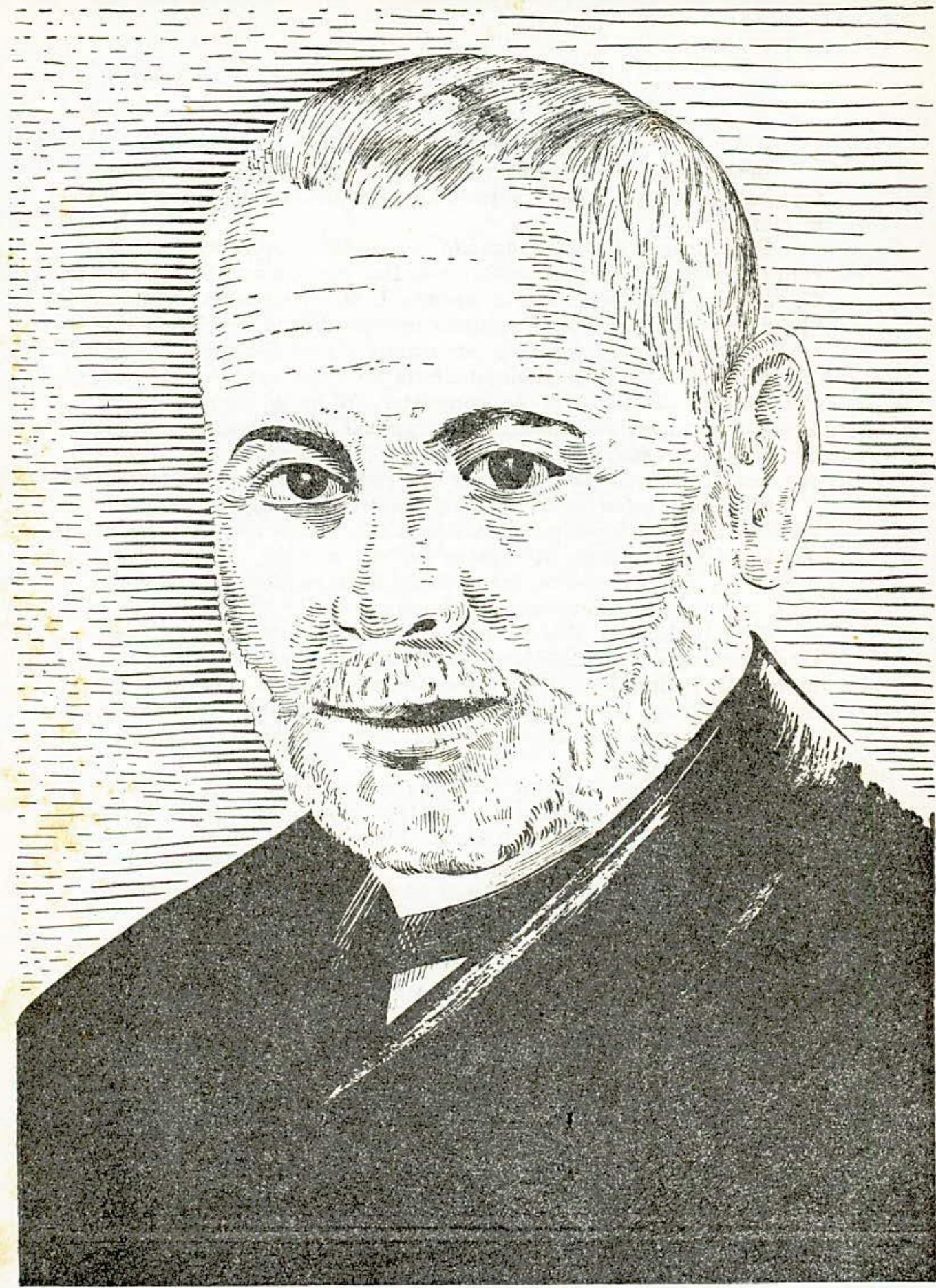

$$
\text { Capistrano de Abrem }
$$


Sendo uma das figuras intelectuais mais brilhantes de seu tempo, gostava de viver na penumbra, esquecido de todos e de si mesmo.

Seus artigos e cartas, quando os assinava, era simplesmente com iniciais: C. A., ou então, C. de A. Por vêzes, simplesmente um C. ou Cap. Não raro, grafava apenas J. N. que queria significar "João Ninguém" e, mesmo, segundo testemunho de seu ilustre discípulo, Prof. Taunay, assinava por extenso "João Ninguém" (19).

Certa ocasião, a singular modéstia do sábio explodiu em reação áspera. Ảs vésperas de completar 70 anos, alguns amigos, ansiosos por festejá-lo, esboçaram organizar um banquete em sua homenagem. Quando a notícia chegou aos ouvidos do Mestre, sua reação foi violenta e em palavras rudes, assim se manifestou:

"Segundo estou informado, trama-se para meu próximo aniversário uma patuléia, poliantéia ou coisa pouco pior e mais ridícula se fôr passível. Aos meus amigos previno que considero a tramóia profundamente inamistosa. Não poderei manter relações com quem assim tenta desmoralizar-me" (20).

Em 1917, Max Fleiuss, então Secretário Perpétuo do Instituto Histórico, sugeriu fôsse conferida uma medaỉha de ouro, prêmio D. Pedro II, ao IMestre Capistrano, pelo seu admirável trabalho de etnografia, Rã-txa-hu-nê-ku-i (a língua dos Caxinauás).

Nem essa honra foi aceita. Em carta íntima a Taunay, escrevia êle:

"Vou hoje ao Instituto Histórico tomar notas para refazer o artigo sôbre os Guaianazes, que será reimpresso na revista de Alberto de Faria. Na mesma ocasião, redigirei um ofício ao Presidente sôbre o tal medalhão de ouro, entaladela bem desagradável, para quem como eu abomina a Satanaz com tôdas suas pompas e obras" (21).

Seu aspecto físico era curioso. Quem o visse, não julgaria estar na presença de um sábio: a barba mal cuidada, os cabelos geralmente crescidos, a roupa surrada e em desalinho, os olhinhos míopes, quase sempre apagados, semi-cerrados, aparentemente sonolentos, na realidade voitados para o riquíssimo mundo interior.

Um poeta, desta forma pintou o retrato de Capistrano:

$$
\begin{aligned}
& \text { "...êste é Capistrano, o bem amado, } \\
& \text { Velho erudito, vivo dicionário } \\
& \text { da História Pátria, mal encadernado" (22). }
\end{aligned}
$$

Pelo fato de viver ensimesmado em profundas meditações culturais, realizando aquelas prodigiosas sinteses de raciocínio que

\footnotetext{
(19). - Afonso Taunay, Algurnas cartas de Capistrano de Abreu, in "Mensário do

(20). - Pandiá Calógeras, discurso proferido na Sessão do Instituto Histórico Brasileiro de 13 de setembro de 1827, in "Anais do Museu Paulista", tomo III, pág. 22, São Paulo.

(21). - Carta a Taunay de 3 de abrit de 1918, in "Mensátio do Jornal do Comércio", tomo 22, vol. I, pág. 307

(22). - Soneto de Américo Facó, apud Rodrigo Ot́́vio Filho, A vida do Capistrano de Abreu, in "Jomal do Comércio" de 27 de setembro de 1953.
} 
o notabilizaram, afastou-se das pequeninas convenções da vida rotineira e das frivolidades sociais, tornando-se uma figura excêntrica.

A excentricidade de Capistrano estendia-se a todos os aspectos de sua vida. Tendo enviuvado muito cêdo, passou a viver solitário, num porão desordenado, onde os livros e manuscritos raros se misturavam a objetos de cozinha, pencas de bananas, à rêde índia onde dormia e estudava e à peças de uso pessoal.

Figuras ilustres procuravam-no assiduamente nesse porão, esquecendo ao brilho de sua conversação erudita, a pobreza e a desordem do ambiente.

Esse mesmo porão é hoje o templo onde se cultua a memória do grande Capistrano, pois é a sede da "Sociedade Capistrano de Abreu", associação formada por amigos e discípulos do Mestre e que visa preservar e difundir o valioso patrimônio cultural que êle nos legou.

Como historiador, Capistrano teve também suas originalidades e exquisitices Não tinha grandes simpatias por Tiradentes. Nunca escreveu sôbre o Mártir da Inconfidência. Nos seus Capítưlos não figurou a Conjuração Mineira, que, para êle, não passou de "conversas ociosas", que apenas pairou no plano das idéias. Não chegou a ser um acontecimento.

Em 1906, Capistrano deu a um amigo os originais dos Capítulos da História Colonial, para que opinasse sôbre êlès. Quando lhe devolveu o trabalho, estranhou o amigo a ausência de Tiradentes naquele estudo. E o Mestre redarguiu, brusco e impertinente: "Vejo que perdi o meu Latim. Se você não viu o que eu quis fazer, que fará o público? Pois a única coisa que eu tive mesmo em vista, foi o seguinte: mostrat que se pode escrever tôda a História do Btasil, sem se nomear sequer o nome de Tiradentes" (23).

Sua curiosa implicância contra Tiradentes, por reflexo, fá-lo quase simpatizar com Silvério dos Reis.

E' assim que se expressa sôbre êste último: "Joaquim Silvério foi apenas um, entre as muitos delatores: só para não se confundir na chusma, alega estas coisas, e, como de todas foi o que mais proveito colheu, a História o tem salientado de modo injusto. Não será para estranhar que algum jovem nortista, intrigado pelas honras prestadas a Tiradentes, em detrimento dos Mascates e dos Republicanos de 17, se proponha a provar que Silvério foi um benemérito, porque a Conjuração Mineira nunca adquiriu uma arma, nem passou de conversas ociosas, queria a desmembração do Brasil e não sua unidade, avançava um movimento destinado a falhar miseràvelmente"... (24).

(23). - Alba Cenazares Nascimento, Capistrano de Abreu, F. Briguet Editôres. Rio, 1931. (24). - João Capistrano de Abreu, Ensaios e Estudos, 3a. série, pág. 184. 
E termina indagando: "já não se fêz coisa semelhante com Calabat?" (25).

Capistrano foi, sobretudo e acima de tudo, um homem independente. Não pensava $\mathrm{ccm}$ a maioria, nem com as correntes de pensamento que estavam em moda. Não cortejava políticos nem disputava posições.

Jamais foi acomodaticio ou convencional. Combateu energicamente a bajulação e a hipocrisia. Sempre insubmisso, jamais contemporizou com a rotina e o êrro. Foi severo na crítica e avêsso à superficialidade. Por vêzes, era áspero, como a caatinga do sertão cearense, onde nasceu, há exatamente 100 anos atrás. Para os amigos, porém, seu coração aninhava tesouros de afetividade.

Sua obra, se aparentemente é dispersiva, por ter êle se dedicado não só à História, como à Geografia, à Etnografia, à Linguística, à Crítica, à Sociologia e à Filosofia da Flistória, tem, entretanto, um denominador comum: a brasilidade. Quer num campo científico, quer noutro, sempre se dedicou às coisas do Brasil, à sua terra, à sua gente.

E, em todos os setores da Ciência em que aplicou sua prodigiosa inteligência e erudição, sempre fêz obra criadora.

Era sua forma particular de amar e servir à Pátria.

MAFALDA P. ZEMELLA

Doutora em Ciências. Auxilias de Ensino da Cadeira de História da Civilização Brasileira da Faculdade de Filosofia, Ciências e Letras da Universidade de São Paulo.

(25). - Idem, ibidem. 